\title{
Influence of Nanosized AIN Powders on the Microstructure, Brazeability, and Tensile Properties of Al-based Filler for Low Temperature Al/Cu Dissimilar Brazing
}

\author{
Do Hyun Jung and Jae Pil Jung* \\ Dept. of Materials Science and Engineering, University of Seoul, Seoul 02504, Republic of Korea
}

\begin{abstract}
This study examined the influence of nanosized aluminum nitride (AlN) powders $(0,0.01,0.05$, 0.10, 0.30, and 0.50 wt\%), on an Al4047-based filler metal. Nanosized AlN powders were dispersed uniformly into the filler metal by a mechanical mixing and melting route using a stainless steel propeller. The influences of nanosized AlN powders on the melting behavior, microstructure, brazeability, and tensile properties were examined, and interfacial reactions between aluminum and copper were carried out. The experimental results showed that the thicknesses of Si and IMC keep decreasing with additions of nanosized AlN powders up to $0.10 \%$ in the brazing filler metal, which is attributed to the adsorption theory of nanosized AlN powders on the surface of Si and IMCs. In addition, the AlN-reinforced filler metal with $0.10 \mathrm{wt} \%$ samples showed a $2.61 \%$ enhancement in wettability due to the decreased surface tension in the filler metal matrix in the presence of nanosized AlN powders. Furthermore, aluminum to copper dissimilar brazing with $0.10 \mathrm{wt} \%$ AlN-reinforced filler metal showed a $16.07 \%$ improvement in the tensile strength compared to the $0 \%$ AlN filler due to the grain refinement of a filler metal matrix by the Orowan strengthening effect.
\end{abstract}

(Received July 3, 2018; Accepted July 26, 2018)

Keywords: brazing, AlN-reinforced filler, brazeability, tensile strength, grain refinement

\section{INTRODUCTION}

Aluminum and its alloys have been used widely in various fields, such as material, electronics, aerospace, and structural industries due to their outstanding mechanical, thermal, and electrical properties, lightweight characteristics, and corrosion resistance [13]. Therefore, the bonding technology of $\mathrm{Al}$ and its alloys is the most important consideration in the $\mathrm{Al}$ industry because higher reliability of $\mathrm{Al}$ cannot be achieved without appropriate bonding technology. This suggests that adequate bonding with a higher property of Al and its alloy is essential for accomplishing outstanding Al bonding. Some of the bonding technologies of $\mathrm{Al}$ and its alloy used in $\mathrm{Al}$ industries are mechanical bonding, adhesive bonding, welding,

*Corresponding Author: Jae Pil Jung

[Tel: +82-2-6490-2408, E-mail: jpjung@uos.ac.kr]

Copyright (c) The Korean Institute of Metals and Materials and brazing. Among them, $\mathrm{Al}$ brazing is one of the most notable Al bonding technologies due to its higher bonding strength and productivity. In addition, an important advantage of brazing enables not only bonding of similar materials but also bonding of dissimilar metals or ceramics with filler metals. In the brazing technology, a brazing joint is formed by melting a filler metal that has a melting temperature higher than $450{ }^{\circ} \mathrm{C}$ without melting the base metal.

Generally, the conventional Al filler metal, which is Al4047 based on Al-12 wt $\% \mathrm{Si}$, is used in the brazing industry because $\mathrm{Si}$ decreases shrinkage defects and increases the fluidity of the molten filler metal. However, the melting temperature of the conventional filler is approximately $570{ }^{\circ} \mathrm{C}$, which is very close to $\mathrm{Al}$ and its alloys. This causes localized melting and degradation of the base metal after brazing, which degrades the brazed joint with cracks and failure at the joint [4]. Moreover, the formation of large $\mathrm{Si}$ particles becomes a serious issue at the joint due to 
brittleness. Therefore, the development of a new filler metal with a lower melting point and higher mechanical properties is essential for $\mathrm{Al}$ brazing.

Some previous studies have reported the development of filler metals with a low melting temperature for $\mathrm{Al}$ brazing. Humpston et al. suggested an Al-20 wt $\% \mathrm{Cu}-2$ $w t \% \mathrm{Ni}-5 \mathrm{wt} \% \mathrm{Si}$ filler with a melting temperature of approximately $525.85^{\circ} \mathrm{C}$ [5], and Suzuki et al. also examined a Al-4.2 wt\%Si-40 wt $\% \mathrm{Zn}-\mathrm{Sn}$ filler with a melting point of approximately $535^{\circ} \mathrm{C}$ [6]. However, a large amount of $\mathrm{Cu}$ causes a brittle failure at the brazed joint [7]. In addition, $\mathrm{Zn}$ is inappropriate for vacuum brazing because of its higher vapor pressure. Kayamoto et al. developed an Al-Ge-Si-Mg filler system with a melting point of approximately $565{ }^{\circ} \mathrm{C}$ [8]. However, the cost of $\mathrm{Ge}$ is too high to use in the brazing process.

The brazing of aluminum and copper is mainly used in automobile, structural, and particularly heat exchanger industries. In this combination, the formation of $\mathrm{CuAl}_{2}$ intermetallic compounds (IMCs) becomes an issue because it can result in cracks and pores at the brazed joint $[9,10]$. Therefore, it is essential to suppress the IMC growth and refine the $\mathrm{Si}$ particles in the filler metal.

A method with the most potential for suppressing IMCs and refining $\mathrm{Si}$ particles in the matrix is the addition of nanosized materials in the filler metal that improves the mechanical properties as well as the brazeability owing to the higher surface energy of the nanosized materials [11-13]. According to Hausner et al., low temperature brazing was achieved using $\mathrm{Ag}$ nanopaste, but the cost of Ag is always a big issue [14]. In addition, Karantzalis et al. reported the addition of nanosized $\mathrm{TiC}$ powders in the $\mathrm{Al}-\mathrm{Si}-\mathrm{Cu}$ system to increase the wettability of the filler metal. However, the IMC growth caused degradation of the brazed joint [15]. Although there have been some studies on the nano-reinforced Al filler metal, no study has reported using nanosized aluminum nitride (AlN) powder in the filler metal for $\mathrm{Al}$ and $\mathrm{Cu}$ dissimilar brazing for heat exchanger applications. AlN, which is non-toxic ceramic material, is regarded as a promising material owing to its lightweight characteristics, superior electrical properties, low cost, and excellent corrosion resistance [16,17].

This study developed a new Al filler metal with nanosized AlN powders with a low melting point and high mechanical properties to minimize the abovementioned problems of existing $\mathrm{Al}$ fillers. Here, $\mathrm{Sn}$ and $\mathrm{Cu}$ act to increase the brazeability and decrease the melting temperature, respectively. Moreover, the influence of nanosized AlN powders in the filler metal on the microstructure, melting behavior, brazeability, and tensile properties of $\mathrm{Al}$ and $\mathrm{Cu}$ dissimilar brazing is examined.

\section{EXPERIMENTAL PROCEDURES}

\subsection{Preparation and fabrication of AIN-} reinforced filler

Al4047 filler metal and pure $\mathrm{Al}, \mathrm{Cu}$, and $\mathrm{Sn}$ were prepared to fabricate a new filler metal (Al-11 wt\% $\mathrm{Si}-19 \mathrm{wt} \% \mathrm{Cu}-2 \mathrm{wt} \% \mathrm{Sn})$ for $\mathrm{Al}$ and $\mathrm{Cu}$ dissimilar brazing. Nanosized aluminum nitride (AlN) powder with an average particle diameter of $100 \mathrm{~nm}$ was also selected as a reinforcement material with a various amounts of AlN $(0,0.01,0.05,0.10,0.30$, and $0.50 \mathrm{wt} \%$ ). Table 1 lists the new filler metals used in this study.

Table 1. AlN-reinforced filler metal with different weight percentages of AIN.

\begin{tabular}{ccc}
\hline Sample & Metal matrix & $\begin{array}{c}\text { Nano-sized AlN } \\
\text { powder }(\mathrm{wt} \%)\end{array}$ \\
\hline$\# 1$ & & 0 \\
$\# 2$ & & 0.01 \\
$\# 3$ & $\mathrm{Al}-11 \% \mathrm{Si}-19 \% \mathrm{Cu}-$ & 0.05 \\
$\# 4$ & $2 \% \mathrm{Sn}$ & 0.10 \\
$\# 5$ & & 0.30 \\
$\# 6$ & & 0.50 \\
\hline
\end{tabular}

To obtain a homogeneous distribution of AlN in the filler metal, a mechanical mixing and melting route using a stainless steel propeller were employed. Afterward, the filler metals reinforced with nanosized AlN powders were heated by induction furnace at approximately $650{ }^{\circ} \mathrm{C}$ for 10 minutes and stirred by 
the propeller. Finally, AlN-reinforced fillers were casted in a graphite crucible and cooled down to room temperature at $0.2{ }^{\circ} \mathrm{C} / \mathrm{min}$.

\subsection{Characterization of AIN-reinforced filler}

The microstructural analysis of the new filler metal with the various amounts of AlN was investigated using FE-SEM (Hitachi 4800). The AlN-reinforced filler metals were ground using $\mathrm{SiC}$ sandpaper, polished using $\mathrm{Al}_{2} \mathrm{O}_{3}$ suspensions, and subsequently etched using a $10 \mathrm{vol} \% \mathrm{H}_{3} \mathrm{PO}_{4}$ solution for $1 \mathrm{~min}$ to obtain a clear microstructural image of the filler metal. In addition, the compositions of AlN-reinforced fillers were analyzed by EDS and the IMC thicknesses were measured using the Image-Pro 6.0 program.

\subsection{Melting behavior}

The melting points of the AlN-reinforced filler were investigated by DSC. The fillers were heated in $\mathrm{Al}_{2} \mathrm{O}_{3}$ pans from room temperature to $600{ }^{\circ} \mathrm{C}$ at a heating rate of $10^{\circ} \mathrm{C} / \mathrm{min}$ in an $\mathrm{Ar}$ atmosphere to prevent contamination from stray oxygen.

\subsection{Brazeability}

Figure 1 shows the schematic diagram of the spreading test of the filler. The $99.99 \% \mathrm{Cu}$ coupons $(30 \times 30 \times 0.3 \mathrm{~mm})$ were prepared as substrates for the filler spreading test. Ten spreading tests were performed for samples according to the standard of JIS-Z-3197.

Generally, the spreading property of the filler depends on the spreading ratio and angle in the spreading test.

\section{AlN reinforced Al filler}

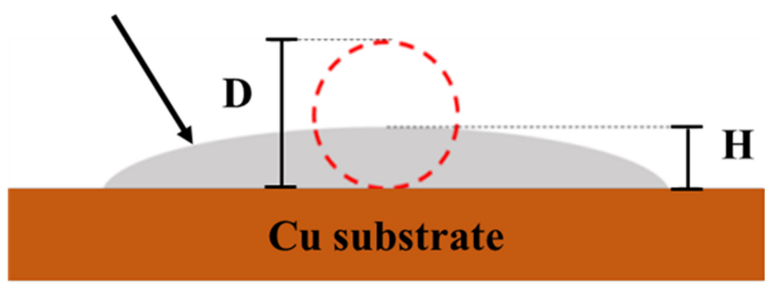

Fig. 1 Schematic diagram of spreading test on $\mathrm{Cu}$ substrate using AlN reinforced filler.
Here, a higher spreading ratio and lower angle indicate better brazeability of the filler; the spreading ratio is calculated according to the equation follow [18].

$$
S=\left(\frac{\mathrm{D}-\mathrm{H}}{\mathrm{D}}\right) \times 100
$$

where $\mathrm{S}$ is the spreading ratio, $\mathrm{D}$ is the diameter of the filler when it is assumed to be a sphere, and $\mathrm{H}$ is the height of the filler after the spreading test.

The spreading test for the filler was as follows. First, the $\mathrm{Cu}$ coupon was polished and cleaned to remove any contamination. Second, the $\mathrm{Cu}$ coupon was pre-heated at approximately $100{ }^{\circ} \mathrm{C}$ for 1 hour to obtain a uniform oxidized $\mathrm{Cu}$. Third, $0.10 \mathrm{~g}$ of various fillers with a noncorrosive Al flux (Lucas Milhaupt, DF751) was placed on the center of the $\mathrm{Cu}$ coupon. Finally, the AlN-reinforced fillers were heated at approximately $530{ }^{\circ} \mathrm{C}$ for 30 seconds using an induction heating furnace and the filler metal was cooled at room temperature.

\subsection{Tensile property}

Figure 2 shows the $\mathrm{Al}$ and $\mathrm{Cu}$ dissimilar brazing sample for the tensile test. A $\mathrm{Cu}$ plate $(60 \times 15 \times 3$ $\mathrm{mm})$ and an Al 3003 plate $(60 \times 15 \times 3 \mathrm{~mm})$ were brazed using an AIN reinforced filler metal with an induction heating furnace. The tensile testing was carried out at a crosshead speed of $0.5 \mathrm{~mm} / \mathrm{min}$ and a strain rate of $0.001 / \mathrm{sec}$ according to ASTM E8 standards. The ultimate tensile strength (UTS) and percent elongation were obtained from the stress-strain curves after the tensile testing. For accuracy, five samples were tested for each condition.

\subsection{Aluminum and copper dissimilar brazing} $\mathrm{Al}$ and $\mathrm{Cu}$ dissimilar brazing using the AlN-

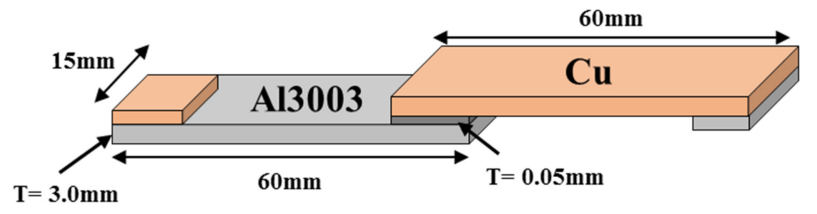

Fig. 2 Schematic diagram of tensile test after $\mathrm{Al} / \mathrm{Cu}$ dissimilar brazing. 
reinforced filler was conducted using an induction heating furnace (PSTEK, HF-15) at an input power of 40 to $60 \mathrm{~kW}$ for 5 to $10 \mathrm{sec}$. A non-corrosive flux for $\mathrm{Al}$ and $\mathrm{Cu}$ brazing was used to prevent any oxidation and improve the wettability of the filler. Afterwards, a microstructural analysis of the brazed joint was conducted to observe the IMC growth behavior and the phases at the joint interface using field emission scanning electron microscopy (FE-SEM), and energy dispersive spectroscopy (EDS). Furthermore, the brazed interface between $\mathrm{Al}$ and $\mathrm{Cu}$ was examined using FE-SEM and EDS.

\section{RESULTS AND DISCUSSIONS}

\subsection{Microstructure of the filler metal}

Figure 3 shows the microstructural images of the filler with various amounts of nanosized AIN powder. Normally, the filler is composed primarily of $\mathrm{Si}$ as well as the $\mathrm{CuAl}_{2}$ IMC. There were large sized $\mathrm{Si}$ (100at\% $\%$ Si) and $\mathrm{CuAl}_{2}$ IMC (Cu-64.79at\%Al) in the $0 \%$ AlN-reinforced filler, as shown in Fig. 3(a). Note also that $\mathrm{Al}$ rich (Al-1.21at $\% \mathrm{Si}-5.13 \mathrm{at} \% \mathrm{Cu}-0.51 \mathrm{at} \% \mathrm{Sn})$ and $\mathrm{Sn}$ rich (Sn-1.75at\%Al-0.28at\%Si-2.14at\%Cu) phases were present in the $0 \%$ AlN-reinforced filler. However, the thicknesses of both $\mathrm{Si}$ and $\mathrm{CuAl}_{2}$ IMCs decreased slightly with the addition of $0.01 \%$ AIN in the filler, as shown in Fig. 3(b). In addition, both the thicknesses of $\mathrm{Si}$ and IMCs continued to decrease by further addition of nanosized AIN powders up to $0.10 \%$ in the filler, as shown in Figs. 3(c) and 3(d).

On the other hand, the thickness of the IMCs began to increase again at $0.30 \%$ AlN in the filler due to the excessive AIN in the filler, as shown in Fig. 3(e). Finally, the IMCs gradually continued to increase up to $0.50 \%$ AIN in the filler, as shown in Fig. 3(f). We inferred that the nanosized AIN powders can affect the morphology and thickness of the $\mathrm{Si}$ as well as $\mathrm{CuAl}_{2}$ IMCs with the optimal amount of AlN in the matrix.

This can be explained by the adsorption theory of nanosized AlN powders on the surface of $\mathrm{Si}$ and IMCs [19,20]. According to this theory, the surface
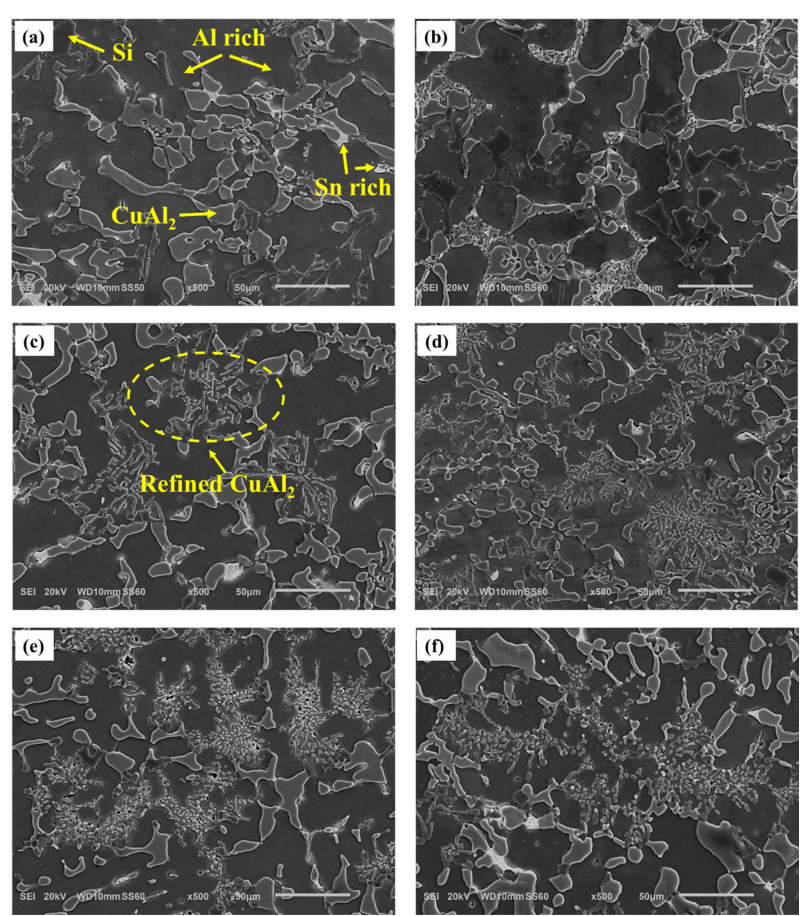

Fig. 3. FE-SEM images of (a) $0 \%$ AIN, (b) $0.01 \%$ AIN, (c) $0.05 \%$ AlN, (d) $0.10 \% \mathrm{AlN}$, (e) $0.30 \% \mathrm{AlN}$, and (f) $0.50 \% \mathrm{AlN}$ in the $\mathrm{Al}$ filler matrix.

free energy of $\mathrm{Si}$ and IMCs decreases and that results in decreasing growth of the IMCs with increases in absorption amounts of surface-active AlN nanosized powders. In other words, nanosized AlN powders act as a type of surface-active materials in the $\mathrm{Si}$ and IMCs and decrease their surface free energy, which results in refined $\mathrm{Si}$ and IMCs. Here, the optimal amount of AIN powders for maximum adsorption on their surface can be expressed as follows [21]:

$$
\Gamma^{K}=-\frac{C}{R T} \frac{d \gamma^{K}}{d C}
$$

where $\Gamma^{K}$ is the amount of nanosized AlN powders which is adsorbed per unit area at the $k$ th plane, $C$ is the total amount of AlN powders, $R T$ is the thermal energy per mole, and $\gamma^{K}$ is the surface energy per unit area of the $k$ th plane without adsorption of AlN powders. From the equation (4), the $k$ th plane indicates the microscopic concept on the surface of the solder. Here, equation (5) can be obtained by integrating equation (4) as follows: 


$$
\gamma_{C}^{K}=\gamma_{0}^{K}-R T \int_{0}^{C} \frac{\Gamma^{K}}{c} d C
$$

where $\gamma_{C}^{K}$ is the surface energy per unit area of the $k$ th plane with adsorption of AIN powders, $\gamma_{0}^{K}$ is the surface energy per unit area of the $k$ th plane without AlN powders. From the equation (5), the whole surface energy can be expressed as follows:

$$
\Sigma_{K} \gamma_{C}^{K} A_{K}=\Sigma_{K}\left(\gamma_{C}^{K}-R T \int_{0}^{c} \frac{\Gamma^{K}}{c} d C\right) A_{K}
$$

where $\Sigma_{K} \gamma_{C}^{K} A_{K}$ is the constant that is independent of concentration and $A_{K}$ is the surface area of the $k$ th plane. Here, it is obvious that $R T \int_{0}^{C} \frac{\Gamma^{K}}{c} d C$ should be maximized for the minimum surface energy. In other words, the growth velocity of a particular plane $k$ will be reduced by the maximum adsorption amount of nanosized AlN powders.

To investigate the influence of nanosized AlN powders on the microstructure of the filler, the average $\mathrm{Si}$ and $\mathrm{CuAl}_{2}$ IMC thicknesses were calculated at different 20 random locations and plotted, as shown in Fig. 4. It is observed that the thickness of $\mathrm{Si}$ was approximately $9.11 \mu \mathrm{m}$ with $0 \%$ nanosized AlN powders in the filler. However, the Si thickness rapidly decreased to $8.57,5.34$, and $5.19 \mu \mathrm{m}$ at 0.01 , 0.05 , and $0.10 \%$ AlN in the filler, respectively.

Afterwards, the thickness gradually increased again by further addition of nanosized AIN powders in the filler

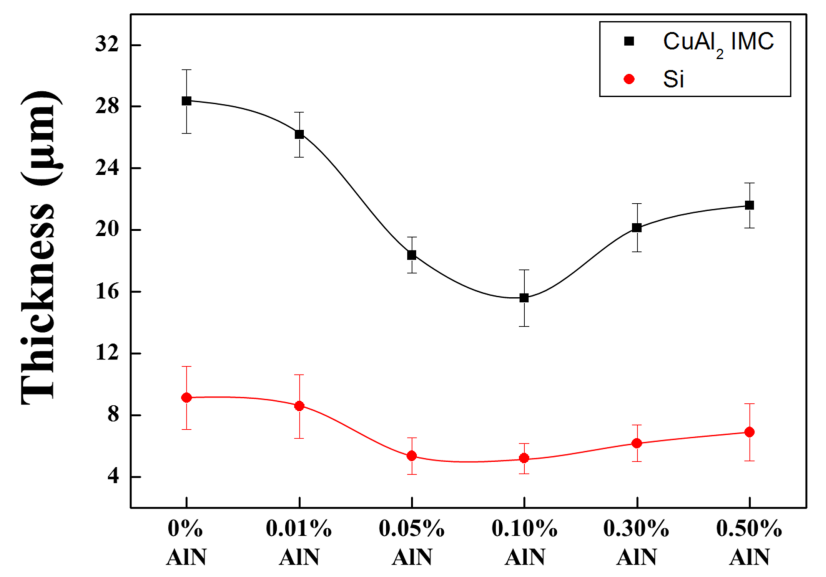

Fig. 4. $\mathrm{CuAl}_{2} \mathrm{IMC}$ thickness and $\mathrm{Si}$ particles size with various $\mathrm{AIN}$ nanoparticle concentrations in the Al filler matrix. to 6.17 and 6.89 at 0.30 and $0.50 \%$ AIN, respectively. In the case of $\mathrm{CuAl}_{2}$ IMC thickness, it was $28.34 \mu \mathrm{m}$ with $0 \%$ nanosized AlN, but it decreased to approximately $26.19,18.37$, and $15.58 \mu \mathrm{m}$ at $0.01,0.05$, and $0.10 \%$ AIN in the filler, respectively. Afterward, the thickness of the $\mathrm{CuAl}_{2}$ IMC increased to 20.14 and $21.59 \mu \mathrm{m}$ after further addition of 0.30 and $0.50 \%$ nanosized AlN powders in the filler, respectively. We inferred that the incorporation of nanosized AlN powders in the filler act as an obstacle of the growth of the $\mathrm{Si}$ as well as the $\mathrm{CuAl}_{2}$ IMC at their optimal amount. This was also due to the adsorption phenomenon by nanosized AlN powders on the surface of the filler owing to the adsorption theory of surface-active metals $[19,20]$.

However, the thicknesses of both the $\mathrm{Si}$ and the $\mathrm{CuAl}_{2}$ IMC increased again after addition of excessive AlN powders in the filler. This is associated with the following reason. An excessive amount of AlN powders in the filler are easily agglomerated due to their reduced inter-particle spacing and higher surface energy [21]. Therefore, bunches of big agglomerated AlN can cause the non-uniform distribution of AlN and pores that result in crack propagation in the filler.

\subsection{Melting behavior}

Figure 5 shows the melting behaviors of the filler with a different amounts of nanosized AlN powder. There were two endothermic peaks and the melting

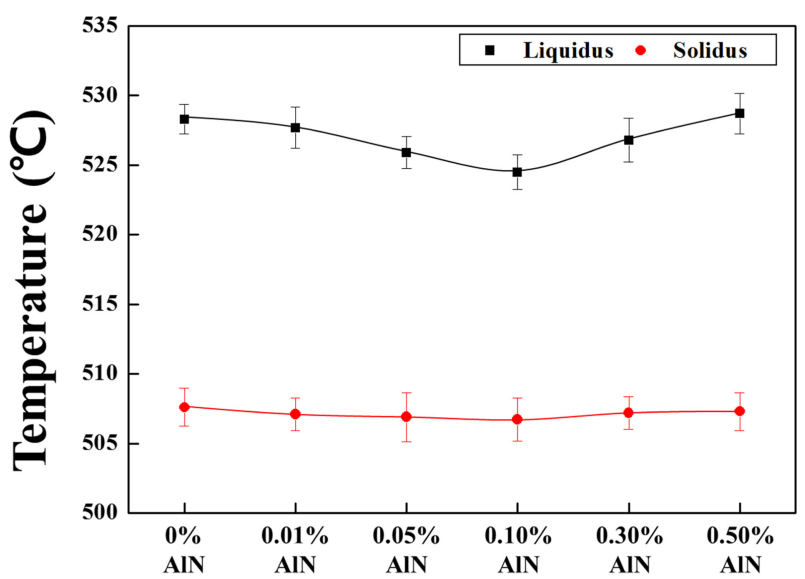

Fig. 5. Melting behaviors of the Al filler matrix with various AIN concentrations. 
temperature of the fillers ranged from 524.5 to $528.7^{\circ} \mathrm{C}$. The liquidus point of the $0 \%$ nanosized $\mathrm{AIN}$ powders in the filler was approximately $528.3^{\circ} \mathrm{C}$. However, it decreased to $527.7,525.9$, and $524.5^{\circ} \mathrm{C}$ with additions of $0.01,0.05$, and $0.10 \%$ AlN in the filler, respectively. Furthermore, the liquidus point increased again to 526.8 and $528.7^{\circ} \mathrm{C}$ at 0.30 and $0.50 \% \mathrm{AlN}$ in the filler, respectively.

This suggests that the presence of nanosized AlN powders in the filler can result in a reduction of the surface energy of an Al filler that causes a drop in the melting temperature. In addition, an increase in the number of surface atoms and phonon vibrations can exceed the atomic average square displacements, which creates a thermal deformation of the lattice, which decreaes the melting temperature [22].

However, the increases in melting temperature with the addition of nanosized AIN powders up to $0.50 \%$ were due to the excessive AIN powders in the filler, which in turn resulted in the agglomeration with a decrease in inter-particle distance. This suggests that the agglomerated AIN powders could not further influence the change in the melting temperature in the filler $[12,13]$. Furthermore, the melting temperature of the filler increased again due to the melt undercooling before solidification of $\mathrm{Al}$ [23].

\subsection{Brazeability}

Figure 6 shows the spreading ratios of the fillers on the $\mathrm{Cu}$ plate with different amouts of AlN. It is known that an increase in the spreading ratio as well as the spreading area means an increase in the brazeability of the filler [24]. The spreading ratio drastically increases with an addition of nanosized AlN powders up to the $0.10 \% \mathrm{AlN}$ in the filler. For example, the spreading ratio gradually increased with the addition of nanosized AIN powders, i.e., the spreading ratio of $74.97 \%$ with $0 \%$ AIN and $75.18 \%$ with $0.01 \%$ nanosized AIN powders. The spreading ratio was $76.36 \%$ in the $0.05 \%$ nanosized $\mathrm{AlN}$ powders in the matrix and $76.93 \%$ in the $0.10 \%$ AIN condition, which is the maximum value of the spreading ratio. The increase in spreading ratio was

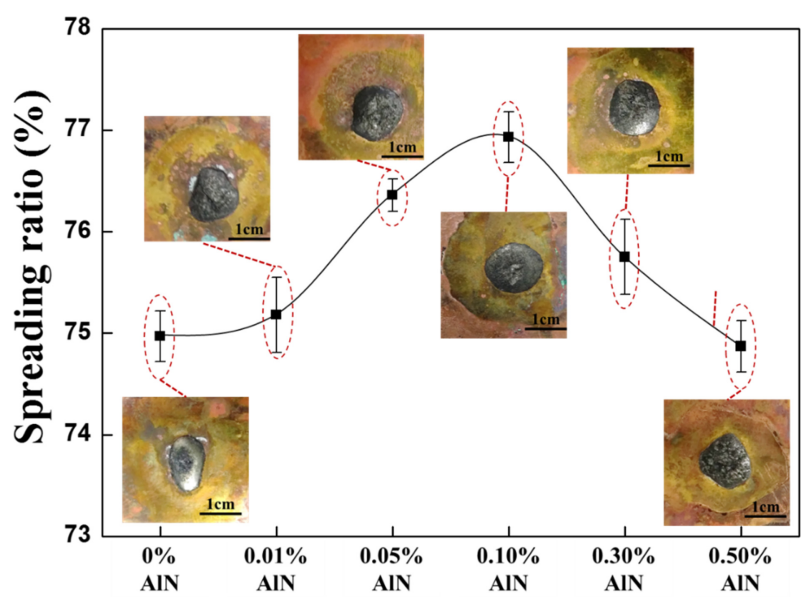

Fig. 6. Spreading ratios of the AlN-reinforced Al filler matrix on the $\mathrm{Cu}$ substrate with various AIN concentrations after the spreading.

due to a uniform distribution of nanosized AlN powders in the filler, which resulted from the decrease in the surface tension and increase in the fluidity of the filler [25]. In addition, this was due to the reduction in the interfacial energy of the AlNreinforced filler in the presence of high energy nanosized AlN powders by suppressing the surface energy of the melt.

However, the spreading ratio gradually decreased again to the 75.75 and $74.87 \%$ in the 0.30 and $0.50 \%$ AlN nanoparticles, respectively, in the matrix. This was due to the non-uniform distribution of AIN powders with many pores during solidification of the filler. In this case, some remaining AIN powders can be floated on the filler. Moreover, excessive AIN powders in the molten metal can cause them to outgas from the melt resulting in segregation of nanoparticles and a poor spreading ratio [20]. Therefore, a higher number of nanoparticles degrades the spreadability of the filler metal. This result is consistent with previous studies on nano-reinforced filler with $\mathrm{La}_{2} \mathrm{O}_{3}$ and $\mathrm{SiC}$ particles [12,13]. From our brazeability results, the optimal amount of filler was revealed as $0.10 \%$ AlN powders in the filler.

\subsection{Tensile property}

Figure 7 shows the tensile strength and elongation curves of $\mathrm{Al} / \mathrm{Cu}$ dissimilar brazed samples with $\mathrm{AlN}$ 


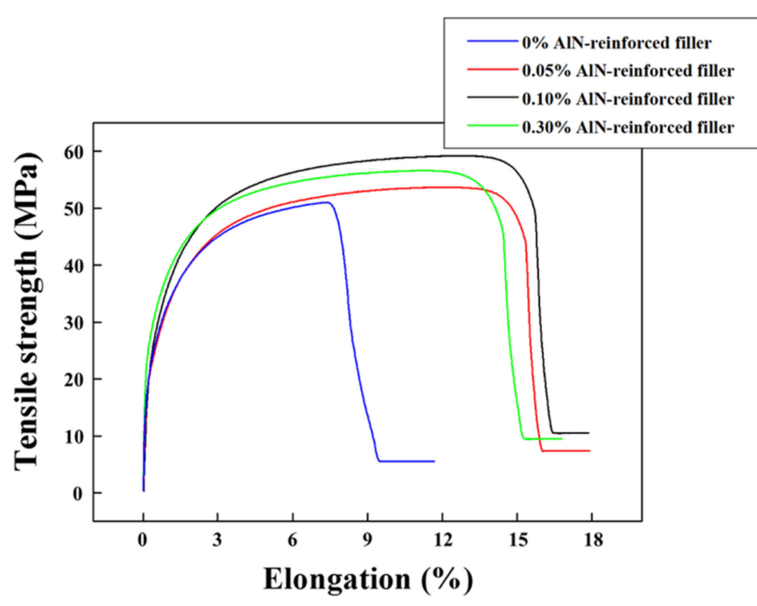

(a)

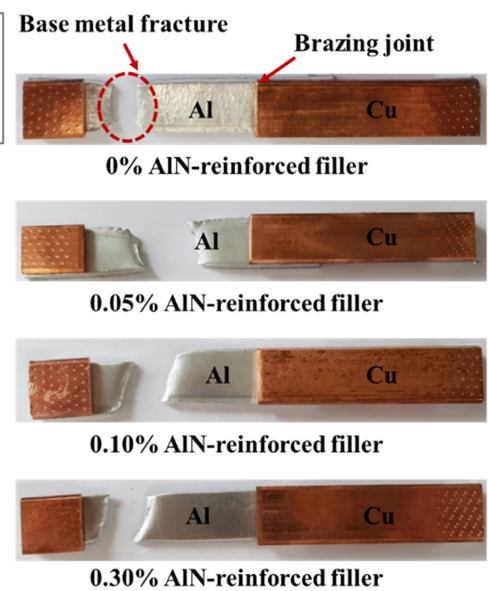

(b)

Fig. 7. (a) Stress-strain curve with a different AIN contents in the Al filler matrix, and (b) the fractured samples after tensile testing.

reinforced filler metal with their fracture specimens after tensile testing. It is observed that all the fractures occurred at the Al3003 side, which indicated a sound brazing property. It is also noted that the tensile strength was $51.03 \mathrm{MPa}$ in the $0 \% \quad \mathrm{AlN}$ nanoparticles and it gradually increased to 53.70 and $59.23 \mathrm{MPa}$ in the 0.05 and $0.10 \%$ AlN nanoparticles, respectively. This increment in tensile strength can be explained by the refinement of eutectic $\mathrm{Si}$ particles and $\mathrm{CuAl}_{2} \mathrm{IMC}$ due to the AlN nanoparticles in the matrix.

This increase in tensile strength of the filler metal by the AIN nanoparticles was due to the combined effect of the four factors, namely, the Hall-Petch equation, effective load carrying capacity, Orowan strengthening effect, and enhanced dislocation density due to the mismatch in CTE between the filler metal matrix and AlN nanoparticles. As the result, these four factors finally led to the increase in tensile strength of the reinforced filler metal by AlN nanoparticles.

However, the tensile strength slightly decreased back to $56.60 \mathrm{MPa}$ with an increase of the AlN nanoparticles to $0.30 \%$ in the matrix. This phenomenon was due to the higher porosity which was caused by excessive AIN nanoparticles and agglomerated AIN nanoparticles in the filler metal matrix, which caused crack propagation and degrading tensile strength of the filler matrix. In other words, the AlN nanoparticles tended to agglomerate to reduce their surface energy if they could not obtain a minimum distance for their uniform dispersion in the matrix [26].

The elongation value was $9.23 \%$ in the $0 \%$ AlN nanoparticles and it drastically increased to $15.81 \%$ and $16.59 \%$ in the 0.05 and $0.10 \%$ AlN, respectively. The increase in elongation of the reinforced filler metal may have been due to the slip mode transition by the AIN nanoparticles, which depends on the interaction of AIN with the interface of the filler metal matrix [27]. Moreover, it may be easy for a plastic deformation to be transformed from dislocation reinforcement shearing to dislocation reinforcement bypassing because of the very small size of the AlN nanoparticles. As a result, AIN nanoparticles can obstruct the movement of dislocation around the interface of the filler metal matrix. On account of the cross-slip formation, the elongation of filler metal can increase by breaking up agglomerates and redistributing AIN [28].

However, the elongation decreases to $15.24 \%$ in the $0.30 \%$ AlN nanoparticles due to the re-distribution of the agglomerated or broken IMCs in the filler matrix by excessive AlN. This suggests that the increase in elongation is associated with the refinement and good dispersion of various phases, such as $\mathrm{Si}$ particles and $\mathrm{CuAl}_{2}$ phases by well distributed $\mathrm{AlN}$ nanoparticles in the filler matrix. 

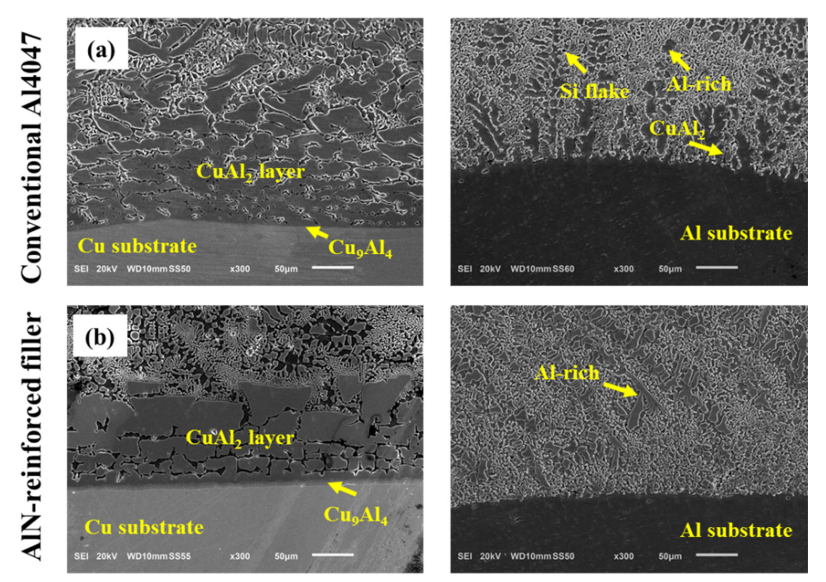

Fig. 8. $\mathrm{Al} / \mathrm{Cu}$ dissimilar brazing using (a) conventional $\mathrm{Al} 4047$ and (b) $0.10 \%$ AlN-reinforced filler matrix.

\subsection{Aluminum and copper brazing with AIN-} reinforced filler

Figure 8 shows the aluminum and copper brazing using a conventional Al4047 and $0.10 \%$ AlN-reinforced filler to compare the microstructure and IMC growth at the brazed joint. In a conventional A14047, it is observed that both the $\mathrm{CuAl}_{2}$ and $\mathrm{Cu}_{9} \mathrm{Al}_{4}$ IMC layers were formed on the $\mathrm{Cu}$ substrate with a mean thickness of 170.79 and $5.14 \mu \mathrm{m}$, respectively. In addition, both $\mathrm{Si}$ particles with a mean length of 4.93 $\mu \mathrm{m}$ and $\mathrm{CuAl}_{2}$ IMC were found on the $\mathrm{Al}$ substrate, as shown in Fig. 8(a).

On the other hand, the mean thickness of both $\mathrm{CuAl}_{2}$ and $\mathrm{Cu}_{9} \mathrm{Al}_{4}$ IMCs using a $0.10 \%$ AlNreinforced filler on the $\mathrm{Cu}$ substrate were 126.17 and $4.71 \mu \mathrm{m}$, respectively, as shown in Fig. 8(b). In addition, the mean length of $\mathrm{Si}$ was approximately $4.18 \mu \mathrm{m}$, which is decreased by $2.64 \%$ as compared to the conventional A14047. This result suggests that AlN nanoparticles in the filler matrix play an important role in the decrease in the IMC thickness as well as the $\mathrm{Si}$ particles due to the adsorption theory [29,30]. In other words, nanosized AlN particles can adsorb on the surface of IMCs and Si particles that result in a decrease in the IMC growth between the filler and substrates because it acts as an obstacle for the interdiffusion of $\mathrm{Cu}$ and $\mathrm{Al}$ atoms.

Figure 9 shows the EDS analysis of the interfacial region using the elemental mapping to determine the composition distribution and inter-diffusion area of the AlN-reinforced filler. It is observed that the interface can be divided into four regions and $\mathrm{Cu}$ is mainly distributed in regions $\mathrm{A}\left(\mathrm{Cu}_{9} \mathrm{Al}_{4}\right)$ and $\mathrm{B}\left(\mathrm{CuAl}_{2}\right)$, while it is detected with a small amount $\mathrm{Cu}$ in regions $\mathrm{C}$ and $\mathrm{D}$ which mean Al-rich constituents.

Consequently, it can be concluded that $\mathrm{Cu}$ is
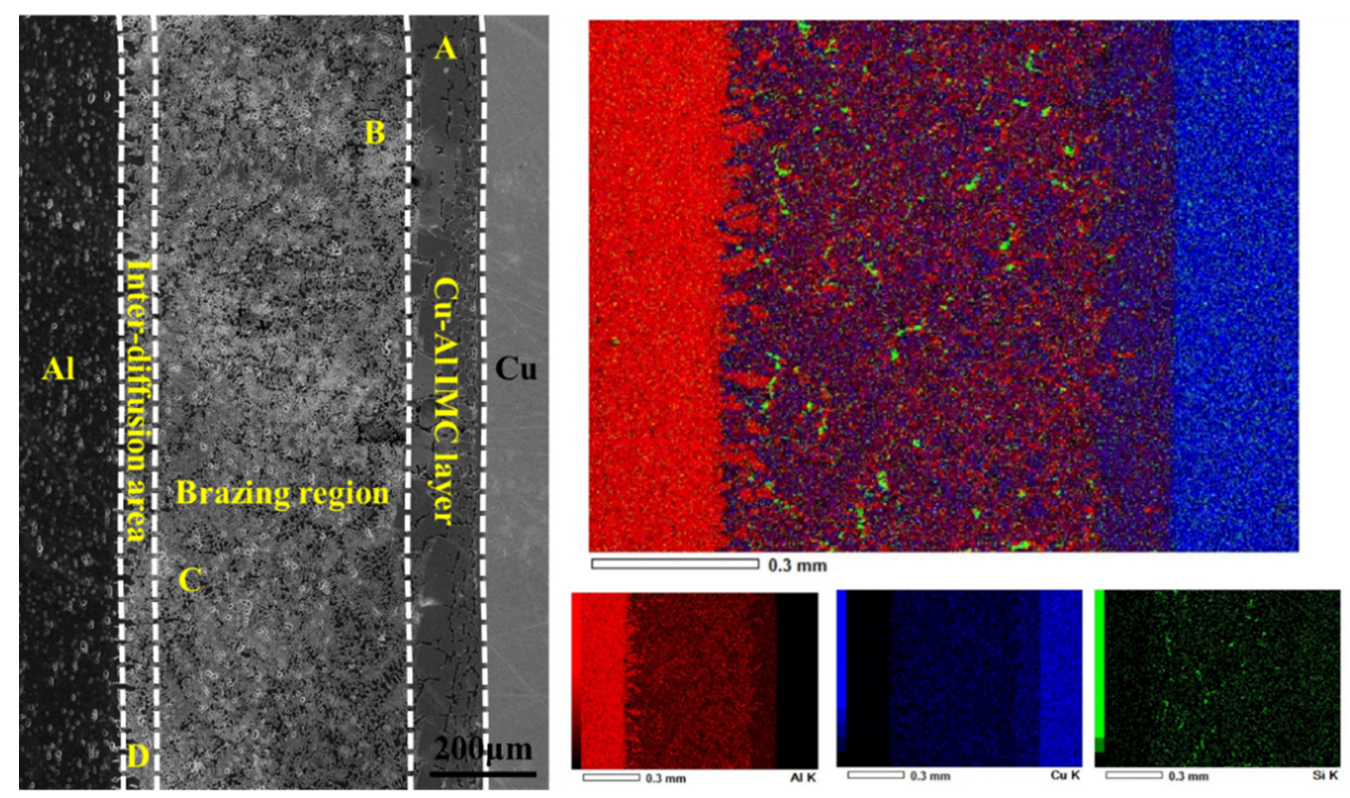

Fig. 9. EDS mapping of the interfacial region after $\mathrm{Al} / \mathrm{Cu}$ dissimilar brazing with $0.10 \% \mathrm{AIN}$ reinforced filler matrix. 
diffused from the $\mathrm{Cu}$ substrate and reacted with the Al filler metal to from a strong bond. The other elements like $\mathrm{Si}$ and $\mathrm{Sn}$ are uniformly distributed at the brazing region.

We also inferred that the both $\mathrm{Al}$ and $\mathrm{Cu}$ substrates are favorably melted and wetted by capillary effect of the filler, which results in a sound metallurgic bonding. In the conventional brazing, an alloy is formed by inter-diffusing from the interface between the base metal and the filler. Normally, higher brazing temperature can result in higher wettability of the filler, owing to the increase in the diffusion coefficient. The relation between the brazing temperature and diffusion coefficient can be expressed by the Arrhenius equation [31].

$$
\mathrm{d}=\sqrt{D t}
$$

where $\mathrm{d}$ is the diffusion length, $D$ is the diffusion coefficient, and $t$ is the brazing time. The diffusion coefficient $(D)$ increases with an increasing heating temperature as follows.

$$
\mathrm{D}=D_{0} \exp \left(-\frac{E_{a}}{R T}\right)
$$

where $D_{0}$ is the constant, $E_{a}$ is the activation energy, $R$ is the gas constant, and $T$ is the Kelvin temperature. If the inter-diffusion between the base metal and molten filler metal is high, a dissolution phenomenon can occur and it is easy to be observed at the $\mathrm{Al}$ brazing process because there is not much difference in the melting point between the $\mathrm{Al}$ filler metal and the Al base metal [32].

\section{CONCLUSION}

The effect of nanosized AlN powders in the $\mathrm{Al}$ filler metal matrix has been studied. The important conclusions are given as follows.

(1) The thicknesses of $\mathrm{Si}$ and IMC keep decreasing with further addition of nanosized AIN powders up to $0.10 \%$ in the filler.

(2) The liquidus point of the $0 \%$ nanosized $\mathrm{AlN}$ powders in the filler was approximately $528.3{ }^{\circ} \mathrm{C}$.
However, it decreased to 527.7, 525.9, and $524.5^{\circ} \mathrm{C}$ with additions of $0.01,0.05$, and $0.10 \%$ AlN in the filler, respectively.

(3) The spreading ratio drastically increases by addition of AlN nanoparticles up to the $0.10 \%$ AlN powders in the filler due to a uniform distribution of nanosized AIN powders in the filler resulting from the decrease in surface tension and increase in the fluidity of the filler.

(4) The tensile strength is $51.03 \mathrm{MPa}$ in the $0 \%$ AIN nanoparticles and it gradually increases to 53.70 and $59.23 \mathrm{MPa}$ in the 0.05 and $0.10 \% \mathrm{AlN}$ nanoparticles, respectively.

(5) At the dissimilar brazed joint between $\mathrm{Al}$ and $\mathrm{Cu}$, the growth of both IMC thickness and $\mathrm{Si}$ particles was suppressed by addition of nanosized AIN powders in the conventional Al filler metal matrix.

\section{REFERENCES}

1. T. G. Lee, H. D. Lee, and J. K. Lee, Korean J. Met. Mater. 55, 845 (2017).

2. J. I. Kim, S. W. Jin, J. Jung, H. M. Sung, H. J. Jeong, S. Park, J. W. Park, and H. N. Han, Korean J. Met. Mater. 55, 372 (2017).

3. M. S. Hong, I. J. Park, and J. G. Kim, Met. Mater. Int. 23, 708 (2017).

4. L. C. Tsao, W. P. Weng, M. D. Cheng, C. W. Tsao, and T. H. Chuang, J. Mater. Eng. Perform. 11, 360 (2002).

5. G. Humpston, S. P. S. Sangha, and D. M. Jacobson, Mater. Sci. Technol. 11, 1161 (1995).

6. K. Suzuki, M. Kagayama, and Y. Takeuchi, J. Jpn. Inst. Light Met. 43, 533 (1993).

7. A. Sharma, M. H. Roh, D. H. Jung, and J. P. Jung, Metall. Mater. Trans. A 47, 510 (2016).

8. T. Kayamoto, J. H. Kim, S. Saito, and T. Onzawa, Quart. J. Jpn. Weld. Soc. 12, 495 (1994).

9. F. Stadler, H. Antrekowitsch, W. Fragner, H. Kaufmann, and P. J. Uggowitzer, Int. J. Cast Metal. Res. 25, 215 (2012).

10. C. J. Hang, C. Q. Wang, M. Mayer, Y. H. Tian, Y. Zhou, and H. H. Wang, Microelectron. Reliab. 48, 416 (2008).

11. I. J. Shon, Korean J. Met. Mater. 54, 893 (2016).

12. A. Sharma, M. H. Roh, and J. P. Jung, J. Mater. Eng. Perform. 25, 3538 (2016).

13. A. Sharma, D. U. Lim, and J. P. Jung, Mater. Sci. Technol. 
32, 773 (2016).

14. S. Hausner, S. Weis, B. Wielage, and G. Wagner, Weld. World. 60, 1277 (2016).

15. A. E. Karantzalis, A. Lekatou, E. Georgatis, V. Poulas, and H. Mavros, J. Mater. Eng. Perform. 19, 585 (2010).

16. H. Altuntas, and T. Bayrak, Electron. Mater. Lett. 13, 114 (2017).

17. C. Young and J. Duh, J. Mater. Sci. 30, 185 (1995).

18. Japanese industrial standard, JIS Z-3197 (2012).

19. A. Sharma, H. R. Sohn, and J. P. Jung, Metall. Mater. Trans. A 47, 494 (2016).

20. D. H. Jung, A. Sharma, D. U. Lim, J. H. Yun, and J. P. Jung, Metall. Mater. Trans. A 48, 4372 (2017).

21. D. H. Jung, A. Sharma, and J. P. Jung, J. Alloy. Compd. 743, 300 (2018).

22. D. G. Gromov, S. A. Gavrilov, E. N. Redichev, and R. M. Ammosov, Phys. Solid State 49, 178 (2007).
23. L. C. Tsao and S. Y. Chang, Mater. Des. 31, 990 (2010).

24. I. J. Shon, J. K. Yoon, and K. T. Hong, Korean J. Met. Mater. 56, 1 (2018).

25. A. Sharma and S. Das, Mater. Des. 30, 3900 (2009).

26. S. C. Tjong, Adv. Eng. Mater. 9, 639 (2007).

27. R. J. Arsenault and N. Shi, Mater. Sci. Eng. A 81, 175 (1986).

28. C. S. Goh, J. Wei, L. C. Lee, and M. Gupta, Mater. Sci. Eng. A 423, 153 (2006).

29. Y. Tang, Y. C. Pan, and G. Y. Li, J. Mater. Sci. Mater. Electron. 24, 1587 (2012).

30. Y. Gu, X. Zhao, Y. Li, Y. Liu, Y. Wang, and Z. Li, J. Alloy. Compd. 627, 39 (2015).

31. D. Gupta, K. Vieregge, and W. Gust, Acta. Mater. 47, 5 (1998).

32. Y. Xiao, H. Ji, M. Li, and J. Kim, Mater. Des. 52, 740 (2013). 